\title{
The role of Rnf in Ion gradient Formation in Desulfovibrio alaskensis
}

Luyao Wang, Peter Bradstock, Chuang Li, Michael J McInerney, Lee R Krumholz

Rnf is a membrane protein complex that has been shown to be important in energy conservation. Here, Desulfovibrio alaskensis G20 and Rnf mutants of G20 were grown with different electron donor and acceptor combinations to determine the importance of Rnf in energy conservation and the type of ion gradient generated. Addition of the protonophore TCS strongly inhibited lactate-sulfate dependent growth whereas the sodium ionophore ETH2120 had no effect, indicating a role for the proton gradient during growth. Mutants in $r n f A$ and $r n f D$ were more sensitive to the protonophore at $5 \mu \mathrm{M}$ than the parental strain, suggesting the importance of Rnf in the generation of a proton gradient. The electrical potential $(\Delta \Psi), \Delta \mathrm{pH}$ and proton motive force were lower in the rnfA mutant than in the parental strain of D.alaskensis $\mathrm{G} 20$. These results provide evidence that the Rnf complex in $D$. alaskensis functions as a primary proton pump whose activity is important for growth. 
5 Department of Microbiology and Plant Biology ${ }^{1}$ and Institute for Energy and the

$9 *$ Corresponding author:

10 Department of Microbiology and Plant Biology, The University of Oklahoma,

11770 Van Vleet Oval, Norman, OK 73019, USA

12 Tel: 405-325-0437 Fax: 405-325-7619 Email: krumholz@ou.edu

13 Contents category: Microbial metabolism

14

15

16

17

18

19

20

21

22

23

24

25

26

27 
ABSTRACT

29 Rnf is a membrane protein complex that has been shown to be important in energy

30 conservation. Here, Desulfovibrio alaskensis G20 and Rnf mutants of G20 were grown

31 with different electron donor and acceptor combinations to determine the importance of

32 Rnf in energy conservation and the type of ion gradient generated. Addition of the

33 protonophore TCS strongly inhibited lactate-sulfate dependent growth whereas the

34 sodium ionophore ETH2120 had no effect, indicating a role for the proton gradient

35 during growth. Mutants in $r n f A$ and $r n f D$ were more sensitive to the protonophore at 5

$36 \mu \mathrm{M}$ than the parental strain, suggesting the importance of Rnf in the generation of a

37 proton gradient. The electrical potential $(\Delta \Psi), \Delta \mathrm{pH}$ and proton motive force were lower

38 in the rnfA mutant than in the parental strain of D.alaskensis G20. These results provide

39 evidence that the Rnf complex in D. alaskensis functions as a primary proton pump

40 whose activity is important for growth.

41 
42 The Rnf complex was first discovered in Rhodobacter capsulatus and is thought to be

43 transcribed in one cluster of seven genes rnfABCDGEH (Jouanneau et al., 1998).

44 Evidence that depleting one subunit could destabilize others indicated the formation of a

45 complex (Kumagai et al., 1997) which was later shown to be a protein complex

46 involved in the Rhodobacter nitrogen fixation process (Schmehl et al., 1993). The Rnf

47 complex has been differentiated into three major groups based on gene organization

48 (Biegel et al., 2011). The first group found in R. capsulatus, Pseudomonas stutzeri (Yan

49 et al., 2008) and Azotobacter vinelandii (Curatti et al., 2005) with rnfABCDGE.

50 Another group with the gene order rnfCDGEAB is found in A.woodii (Biegel et al.,

51 2009) and Clostridium kluyveri (Seedorf et al., 2008). Lastly rnfBCDGEA is found in

52 Chlorobium limicola, Bacteroides vulgatus and Prosthecochloris aestuarii (Biegel et al.,

53 2011).

54 Rnf complex has been shown to be a novel type of ferredoxin-dependent enzyme,

55 catalyzing the oxidation-reduction reaction between reduced ferredoxin and $\mathrm{NAD}^{+}$

56 (Biegel et al., 2009; Boiangiu et al., 2005). Because of the high sequence similarity to

57 the $\mathrm{Na}^{+}$-translocating $\mathrm{NADH}$ :ubiquinone oxidoreductase (Nqr) (Kumagai et al., 1997),

58 the Rnf complex in R. capsulatus was suggested to be involved in ion translocation

59 using the energy from the exergonic reduction of $\mathrm{NAD}^{+}$coupled to the oxidation of

60 reduced ferredoxin (Müller et al., 2008). Based on the above similarity, Rnf was

61 originally proposed to be a sodium pump (Biegel et al., 2009). This theory was

62 strengthened after the Rnf complex in Acetobacterium woodii was confirmed to

63 generate a $\mathrm{Na}^{+}$gradient when carrying out the redox reaction between reduced

64 ferredoxin and $\mathrm{NAD}^{+}$(Biegel \& Müller, 2010). However, the Rnf complex was 
65 suggested to be a proton-translocating ferredoxin:NAD ${ }^{+}$oxidoreductase in Clostridium

66 ljungdahlii (Kopke et al., 2010) and was more recently shown to produce a proton

67 gradient (Tremblay et al., 2013). It therefore appears that Rnf may pump different ions

68 in different bacteria (Hess et al., 2016).

69 Desulfovibrio alaskensis G20 encodes the Rnf complex with a unique gene

70 arrangement ( $r n f C D G E A B F)$; however, a similar Rnf complex is present in most

71 sulfate-reducing bacteria for which genome sequences are available (Pereira et al.,

72 2011). Directly preceding the operon is a decaheme cyctochrome (dhcA) which is also

73 present in many but not all sulfate reducing bacteria The first gene in the $r n f$ operon is a

74 decaheme cytochrome (DhcA) that belongs to cytochrome $c_{3}$ family (Pereira et al.,

75 2011). The final gene in the operon, $r n f \mathrm{~F}$ is most similar to $a p b \mathrm{E}$, a membrane

76 associated lipoprotein (Beck \& Downs, 1999).

77 Recently, it was reported that mutants in Rnf in D. alaskensis are unable to grow

78 using $\mathrm{H}_{2}$ or during syntrophic growth conditions with Syntrophus aciditrophicus or

79 Syntrophomonas wolfeii (Krumholz et al., 2015; Price et al., 2014). By investigating

80 gene expression levels of D.alaskensis G20 grown in pure culture or under syntrophic

81 conditions (Krumholz et al., 2015), it was suggested that both formate and $\mathrm{H}_{2}$ can act as

82 electron shuttles during syntrophic growth. Those experiments also showed that

83 expression of $r n f$ genes are upregulated under syntrophic conditions and during $\mathrm{H}_{2}$

84 dependent growth confirming the role of the Rnf complex in $\mathrm{H}_{2}$ metabolism.

85 In this experiment, mutants of RnfA (Dde_0585) and RnfD (Dde_0582) were

86 studied and compared with the G20 parent strain to determine whether Rnf in $D$.

87 alaskensis is involved in generation of a proton motive force (PMF). These two 
88 mutants of Desulfovibro alaskensis G20 were obtained by using mini Tn10 transposon

89 (Groh et al., 2005) and identified individually during syntrophic growth with

90 Syntrophomonas wolfeii (Krumholz et al., 2015).

\section{MATERIALS AND METHODS}

92 Growth of Cultures. Desulfovibrio alaskensis G20 and rnf mutants were routinely

93 cultured anaerobically $\left(\mathrm{N}_{2}-\mathrm{CO}_{2}, 80: 20\right)$ in basal medium with lactate-sulfate $(50 \mathrm{mM}$

94 each) as the electron donor and electron acceptor, respectively and contained $0.1 \%$ yeast

95 extract (Krumholz et al., 2015). The medium was prepared under a headspace of

$96 \mathrm{~N}_{2} / \mathrm{CO}_{2}(80 / 20, \mathrm{vol} / \mathrm{vol})$ with sodium bicarbonate $(3.5 \mathrm{~g} / \mathrm{L})$ added as a buffer. Before

97 inoculation, the medium was reduced with $0.025 \%$ each cysteine and sulfide.

98 Kanamycin $(1050 \mu \mathrm{g} / \mathrm{mL})$ was added to the mutant cultures. Inoculum consisted of 0.2

$99 \mathrm{ml}$ transferred into $10 \mathrm{ml}$ of media or the same ratio for large volume cultures.

100 Cultures were grown in the incubator at $37^{\circ} \mathrm{C}$ and growth of triplicate cultures was

101 measured by optical density at $600 \mathrm{~nm}$. The stock cultures were frozen in $20 \%$ glycerol

102 at $-20^{\circ} \mathrm{C}$. Growth of syntrophic cocultures was as previously described (Krumholz et

103 al., 2015).

104 Growth was tested with a variety of other electron donors and acceptors: lactate

$105(50 \mathrm{mM})$, pyruvate $(25 \mathrm{mM})$, ethanol $(10 \mathrm{mM})$ and formate $(50 \mathrm{mM})$. Sulfate was used at

$10650 \mathrm{mM}$ with lactate and $25 \mathrm{mM}$ with other electron donors and sulfite was added at

$10710 \mathrm{mM}$.

108 The protonophore 3,3,4,5-tetrachlorosalicylanide (TCS, $5 \mu \mathrm{M}$ or $20 \mu \mathrm{M}$ ), or the

109 sodium-specific ionophore $\mathrm{N}, \mathrm{N}, \mathrm{N}^{\prime}, \mathrm{N}^{\prime}$-Tetracyclohexyl-1,2-phenylenedioxydiacetamide

$110(\mathrm{ETH} 2120,20 \mu \mathrm{M})$ were added to media to test their effects on growth. 
112 Transcriptional analysis of $\boldsymbol{r n} \boldsymbol{f}$ genes. Total RNA was extracted from the parent strain,

$113 r n f A$, and $r n f D$ mutants using the Qiagen RNeasy kit as previously described (Krumholz

114 et al., 2015). Purity and adequate yield was confirmed with a diode-array

115 spectrophotometer. First-strand cDNA synthesis was performed using the Fermentas

116 Revertaid kit with gene-specific primers covering the entirety of the rnf mutants'

117 operons . Primers were designed to span the gaps between each gene in the operon

118 (Table 1). PCR was performed with the parent strain and mutants with each primer set

119 followed by agarose gel analysis to determine whether all genes in the operon were

120 expressed and whether the genes were on the same transcript.

121 Quantitative PCR analysis. Triplicate cultures of the parent strain and $r n f A$ and $r n f D$

122 mutants were grown to mid-log phase $\left(\mathrm{OD}_{600} 0.3-0.45\right)$ and harvested by centrifugation

123 at $5,000 \times \mathrm{g}$ for $5 \mathrm{~min}$ at $4{ }^{\circ} \mathrm{C}$. The pellet was homogenized in RNAprotect Bacteria

124 reagent (QIAGEN) for 5 min at room temperature to prevent degradation of RNA

125 transcripts. Excess liquid was removed by centrifugation and cell pellets were

126 resuspended in 200ul of TE buffer containing $1 \mathrm{mg} / \mathrm{ml}$ lysozyme. Total RNA was

127 extracted using the RNeasy mini kit (QIAGEN). RNA was then treated with the

128 Ambion Turbo DNA - free kit (Thermo) to eliminate genomic DNA contamination.

129 RNA was quantified spectrophotometrically. cDNAs were synthesized using the First

130 Stand cDNA synthesis kit (Fermentas) as described in the manual. Control PCR

131 reactions were done to ensure there was no genomic DNA or non-specific

132 amplification. 
133 Quantitative PCR, was done in triplicate from each culture replicate using 10ng

134 cDNA as the template and the Maxima SYBR Green qPCR master mix (Thermo) with a

135 MyIQ Cycler (Bio-Rad). Primers were designed using Primer-BLAST (NCBI website)

136 to specifically amplify 128- to 155-bp regions of targeted genes Dde_587, Dde_589,

137 Dde_590 (Table 2). Dde_0587 is the final gene in the rnf operon and the other two

138 genes are the next two ORFs directly downstream of the operon. The 16s rRNA

139 primers were as previously described (Li et al., 2011). Reactions used the following

140 amplification condition: $95^{\circ} \mathrm{C}$ for $10 \mathrm{~min} ; 40$ cycles of denaturation at $95^{\circ} \mathrm{C}$ for $15 \mathrm{~s}$ and

141 annealing/extension at $60^{\circ} \mathrm{C}$ for 1 min. mRNA expression was calculated using $\left(\mathrm{E}_{\text {target }}\right)^{\Delta}$

142 Ct_target (control- mutant) $/\left(E_{\text {reference }}\right)^{\Delta \mathrm{Ct} \_ \text {reference (control- mutant) }}$ (Pfaffl, 2001) The 16s rRNA gene

143 was used for normalization.

144 Washed cell experiments. Washed cells were used to measure sulfide production

145 under non-growth conditions. Briefly, $100 \mathrm{ml}$ lactate-sulfate culture grown to mid

$146 \log$ phase was harvested by centrifugation at $5300 \mathrm{x} \mathrm{g}$ for $15 \mathrm{~min}$, washed twice in

147 buffer containing $50 \mathrm{mM}$ MOPS ( $\mathrm{pH} 7.2), 5 \mathrm{mM} \mathrm{MgCl} 2$ and resuspended in the same

148 buffer. All buffers were flushed with $\mathrm{N}_{2}$ for $30 \mathrm{~min}$. Assays were carried out in

149 serum tubes containing $2 \mathrm{ml}$ of buffer-cell mixture incubated at $37^{\circ} \mathrm{C}$ on a shaker at

$150100 \mathrm{rpm}$. The assay mixture contained the washing buffer, $5 \mathrm{mM}$ sodium sulfate and

151 either $50 \mathrm{mM}$ lactate, $50 \mathrm{mM}$ sodium formate $\left(\mathrm{N}_{2}\right.$ headspace $)$ or $\mathrm{H}_{2}$ in the headspace.

152 Between 50 and $200 \mu \mathrm{g}$ of cell protein was added to each tube. Tubes were sacrificed

153 by addition of $2 \mathrm{ml} \mathrm{10 \%} \mathrm{Zinc} \mathrm{Acetate} \mathrm{at} 60 \mathrm{~min}$ intervals for sulfide analysis. Sulfide

154 was determined using the methylene blue assay (Cline, 1969). 
155 Measurement of proton motive force. Triplicate cultures of D. alaskensis parent strain

156 and rnfA mutant were grown in lactate -sulfate basal medium until mid exponential

157 phase $\left(\mathrm{OD}_{600}\right.$ of 0.5$)$ in a 1 liter volume and $30 \mathrm{ml}$ aliquots of cells were dispensed into

$158100 \mathrm{ml}$ serum bottles under $\mathrm{N}_{2} / \mathrm{CO}_{2}(80 / 20$, vol/vol). The basal medium contains $5 \mathrm{mM}$

$159 \mathrm{~K}^{+}$, mainly added as potassium phosphate salts. Protein concentration was determined

160 using the Bicinchoninic Acid Assay (Pierce BCA Protein Assay Kit).

161 Transmembrane electrical potential $(\Delta \Psi)$ was measured as previously described

162 (Tremblay et al., 2013). Briefly, cells were incubated with

$163\left[{ }^{3} \mathrm{H}\right]$ tetraphenylphosphonium bromide $\left(\left[{ }^{3} \mathrm{H}\right] \mathrm{TPP}^{+}\right)(\mathrm{ARC}, 0.1 \mu \mathrm{Ci} / \mathrm{ml})$ for $15 \mathrm{~min}$ at $37^{\circ} \mathrm{C}$

164 (Kashket \& Barker, 1977; Shirvan et al., 1989). $\left[{ }^{3} \mathrm{H}\right] \mathrm{TPP}^{+}$was dissolved in media and

165 filtered through $0.45 \mu \mathrm{m}$ filters prior to adding to cells. Controls were incubated with

166 nigericin (ACROS ORGANICS, $20 \mu \mathrm{M}$ dissolved in ethanol at 200x) and valinomycin

167 (ACROS), $20 \mu \mathrm{M}$ dissolved in DMSO at 200x) for $15 \mathrm{~min}$ to eliminate the $\Delta \Psi$. The

168 combination of nigericin (proton $/ \mathrm{K}^{+}$antiporter) and valinomycin $\left(\mathrm{K}^{+}\right.$uncoupler) will

169 dissipate the proton gradient (Kessler et al., 1977). Cells were then separated from the

170 medium using silicone oil as described below and $\left[{ }^{3} \mathrm{H}\right] \mathrm{TPP}^{+}$was determined in the

171 liquid scintillation counter (Packard TriCarb 2100TR). The uptake of $\left[{ }^{3} \mathrm{H}\right] \mathrm{TPP}{ }^{+}$was

172 corrected for extracellular contamination using the ratio of the intracellular to

173 extracellular volume as described below. Non-specific binding of $\left[{ }^{3} \mathrm{H}\right] \mathrm{TPP}{ }^{+}$was

174 corrected by subtracting the cell associated $\left[{ }^{3} \mathrm{H}\right] \mathrm{TPP}^{+}$in the valinomycin/nigericin

175 treatment from that in the untreated cells. The $\Delta \Psi$ was calculated with the simplified

176 Nernst equation $(-2.3[\mathrm{RT} / \mathrm{F}] \times \log [$ (concentration in $) /($ concentration out $)])$. 
177 The $\Delta \mathrm{pH}$ was measured by testing the distribution of $\left[{ }^{14} \mathrm{C}\right]$ benzoate (ARC, $1780.4 \mu \mathrm{Ci} / \mathrm{ml}$ ) across the cell membrane after $15 \mathrm{~min}$ incubation at $37^{\circ} \mathrm{C}$ with cells

179 (Kashket \& Barker, 1977; Shirvan et al., 1989). Cells were then separated from the 180 supernatant as described below and $\left[{ }^{14} \mathrm{C}\right]$ benzoate was measured. $\left[{ }^{14} \mathrm{C}\right]$ benzoate 181 uptake was corrected for extracellular contamination using the ratio of intracellular to 182 extracellular volume described below. Tetrachlorosalicylanilide (TCS, $20 \mu \mathrm{M}$ ) was 183 added to controls to eliminate the $\Delta \mathrm{pH}$ and was used to calculate internal $\mathrm{pH}$ in the 184 absence of a $\Delta \mathrm{pH}$. The external $\mathrm{pH}$ was measured, $\left[{ }^{14} \mathrm{C}\right]$ benzoate uptake was 185 quantified and intracellular $\mathrm{pH}$ was calculated with the Henderson-Hasselbach equation 186 (Rottenberg, 1979). The proton motive force (PMF) was calculated using the 187 equation: $\mathrm{PMF}=\Delta \Psi-\mathrm{z} \Delta \mathrm{pH}$. At $37^{\circ} \mathrm{C}$, z equals to 61.48 .

188 Measurement of intracellular volume/total volume of cell pellet. $\quad{ }^{3} \mathrm{H}_{2} \mathrm{O} \quad(1 \mu \mathrm{Ci} / \mathrm{ml})$

189 was used to measure the total pellet volume while $\left[{ }^{14} \mathrm{C}\right]$ taurine (PerkinElmer, $0.5 \mu \mathrm{Ci} / \mathrm{ml}$ )

190 was used to measure extracellular volume and was inferred to penetrate up to the 191 plasma membrane (Kashket \& Barker, 1977). The intracellular water volume was

192 estimated from total pellet water volume minus extracellular water volume by 193 measuring the difference between the distribution of ${ }^{3} \mathrm{H}_{2} \mathrm{O}$ and $\left[{ }^{3} \mathrm{H}\right]$ taurine after 194 incubating cells for $15 \mathrm{~min}$ at $37^{\circ} \mathrm{C}$ with each isotope.

195 Separation of cells from the supernatant. Following the 15 minute incubation with

196 the isotope, three $10 \mathrm{ml}$ aliquots of the total $30 \mathrm{ml}$ solution were put into three $15 \mathrm{ml}$

197 Falcon tubes with $3 \mathrm{ml}$ of a mixture of silicone oils (25\% Fluid 510, 50 centistokes, and $19875 \%$ Fluid 550, 115 centistokes; Dow-Corning Corp, Serva. vol/vol). Cells were then 199 centrifuged at $5300 \mathrm{xg}$ at $4^{\circ} \mathrm{C}$ for $10 \mathrm{~min}$. The aqueous layer and the silicone oil was 
200 removed with a Pasteur pipette connected to a vacuum line. The bottom of the falcon

201 tube containing the cell pellet was cut off and moved into the scintillation vial and the

202 cell pellet was re-suspended with $200 \mu 1$ distilled-water. Liquid scintillation cocktail

203 (PerkinElmer, Ultima Gold) was added prior to scintillation counting.

204 Statistical analysis. Statistical analysis used either the t-test or a one-way analysis of 205 variance (ANOVA) with the Tukey’s Range test.

\section{RESULTS}

207 Mutants in the rnf operon. In a previous study, a Tn10 mutant library of $D$.

208 alaskensis G20 was screened for the ability to grow on butyrate in coculture with

209 Syntrophomonas wolfei (Krumholz et al., 2015). Seventeen mutants were obtained

210 that were deficient in syntrophic growth. Of these, two mutants had the transposon

211 insertions within a putative $r n f$ operon. This operon is composed of 8 genes located on

212 the genome as shown in Table 3 and genes appear to be co-transcribed. They are

213 separated from the nearest upstream transcribed region by $185 \mathrm{bps}$ and from the nearest

214 downstream transcribed region by 342 bps. The two syntrophy mutants had

215 transposon insertions within $r n f \mathrm{~A}$ and $r n f \mathrm{D}$ as determined using Arbitrary PCR

216 (Krumholz et al., 2015). Both genes encode integral membrane proteins likely located

217 in the cytoplasmic membrane. RnfD has been previously shown to bind a flavin

218 (Biegel et al., 2011).

219 Transcriptional analysis of the rnf operon. The complete transcriptional analysis for

220 strain $\mathrm{G} 20$ under lactate-sulfate, $\mathrm{H}_{2}$-sulfate and under syntrophic growth conditions has

221 been previously published (Krumholz et al., 2015). Here we present a summary of

222 normalized values for transcription of each subunit within the rnf operon (Table 3). 
223 Transcription of all genes in the operon including $d c h A$ are similar under each condition

224 and are affected similarly by growth condition. The most highly expressed genes are the

225 first two in the operon, the gene for the cytochrome c family protein and $r n f C$, both of

226 which have 1.5-2 fold higher levels of expression than genes for the other subunits.

227 Expression was also enhanced approximately 2-fold when cultures were grown on $\mathrm{H}_{2}$,

228 relative to lactate, indicating the importance of this protein for $\mathrm{H}_{2}$ dependent growth.

229 Syntrophic cultures had enhanced expression of all eight genes compared to

230 lactate/sulfate growth with similar levels of expression in the S. aciditrophicus coculture

231 to $\mathrm{H}_{2}$-grown cells and higher levels of expression observed in the $S$. wolfei coculture,

232 indicating the importance of this protein complex under syntrophic conditions. Similar

233 effects on transcription provide evidence that all eight genes are located in one operon.

234 Expression analysis of rnf operons in mutants. To determine whether the

235 transposon insertion eliminated downstream expression of genes in the $r n f$ operon, gap

236 analysis was performed where all intergene regions were amplified except the region

237 between $r n f B$ and $r n f A$ using cDNA prepared using mRNA. All of the intergene

238 regions were amplified for the parent and the two mutants (Fig. S1) confirming that

239 all 8 genes form an operon and indicating that the mutants likely have intact transcripts

240 of the interrupted operon. In this operon, the insertions are likely only affecting the one

241 interrupted gene.

242 We carried out RT-PCR analysis of the terminal gene in the operon, Dde_587 (rnfF)

243 as well as the two genes that followed that operon, Dde_589 (uspA) and Dde_590 (cls)

244 to be certain that downstream expression was not affected by the insertions.

245 Expression of the terminal gene in the operon was impacted in the mutants with a 
2464 fold decrease in expression in the rnfA mutant and a 2 fold increase in the $r n f D$

247 mutant (Table 4). The following 2 genes were minimally impacted indicating that

248 the insertions present in the mutants likely do not affect downstream expression.

249 Growth and sulfate reduction by rnf mutants. The two mutants exhibited similar

250 growth rates to that of the parent strain when lactate was the electron donor with sulfate

251 (Fig. 1A) or sulfite as electron acceptor (Fig. 1B). When pyruvate was the donor,

252 growth yields were reduced for the mutants (Fig. 1C). We previously reported that $r n f$

253 mutants grew poorly (rnfD) or not at all (rnfA) on $\mathrm{H}_{2}$ (Krumholz et al., 2015) and a

254 recent study has reported that rnf mutants grow poorly or not at all with sulfate as the

255 electron acceptor on malate, fumarate, ethanol, hydrogen, and formate, but growth is

256 not affected in lactate and pyruvate (Price et al., 2014). Here, it is shown that the $r n f D$

257 mutant has a long lag phase with formate as the donor, but eventually grew to a similar

258 OD to the parent strain (Fig. 1D). The rnfA mutant did not grow on formate or $\mathrm{H}_{2}$

259 clearly indicating the involvement of $\mathrm{Rnf}$ in formate/ $\mathrm{H}_{2}$-dependent growth. We also

260 confirmed that the rnfA mutant will not grow on ethanol (Fig. S3).

261 Sulfide production by washed cells. Washed cells were used to determine if the role for

$262 r n f$ was linked to biosynthesis, as mutants were able to grow better on more complex

263 carbon compounds. Incubations of washed cells of the parent strain and the rnf $A$

264 mutant produced 0.57 and $0.17 \mu$ mol sulfide. $\mathrm{hr}^{-1} \cdot \mathrm{mg}^{-1}$ protein respectively with lactate

265 as electron donor. Addition of either $5 \mu \mathrm{M}$ TCS to the washed cells of the parent

266 strain prevented $95 \%$ of the sulfide production and addition of $20 \mu \mathrm{M}$ to washed cells

267 inhibited sulfide production by $100 \%$, suggesting TCS directly disrupts the proton

268 gradient needed for respiration. With $\mathrm{H}_{2}$ as the electron donor, parent strain cells 
269 produced $0.30 \mu \mathrm{mol}$ sulfide. $\mathrm{hr}^{-1} \cdot \mathrm{mg}^{-1}$ protein whereas the $r n f A$ mutant did not have any

270 detectable activity. To further test whether the lack of growth on $\mathrm{H}_{2}$ was due to the

271 mutant's inability to biosynthesize carbon intermediates, we attempted to grow the

272 mutant and the parent strain with $\mathrm{H}_{2}$ as the electron donor with $0.1 \%$ Casamino acids

273 added to the media. The mutant would still not grow (Fig. S4), providing further

274 evidence that the role for RNF was not directly linked to biosynthesis.

275 Growth curves with ionophores. The sodium ion ionophore ETH 2120, tested at 20

$276 \mu \mathrm{M}$, did not have a significant influence on the growth of the parent strain or the $r n f$

277 mutants with lactate as the electron donor whether sulfate or sulfite were present as

278 electron acceptors (Fig S5,S6). Interestingly, the protonophore, TCS , at $5 \mu \mathrm{M}$

279 differentially inhibited cultures (Fig. 2). TCS partially inhibited the growth of the parent

280 strain and completely inhibited the growth of $r n f$ mutants on lactate-sulfate (Fig. 2A and

281 Fig. S5). Growth on lactate sulfite was then tested and $5 \mu \mathrm{M}$ TCS was shown to have

282 a smaller but still significant inhibitory effect on growth in the parent strain (Fig. 2B)

283 and again completely inhibited the $r n f A$ mutant (Fig. 2B, S6). A higher level of TCS

284 was then tested and it was shown that $20 \mu \mathrm{M}$ TCS almost completely inhibited the

285 growth of the parent strain on lactate-sulfite (Fig. 2B) and again completely inhibited

286 the mutants (Fig. S7).

287 Measurement of $\triangle \Psi, \Delta p H$ and PMF. To determine whether the Rnf complex is

288 involved in the formation of a proton gradient, the transmembrane potential $(\Delta \Psi), \Delta \mathrm{pH}$

289 and proton motive force (PMF) were measured in cells of the G20 parent strain and the

290 rnfA mutant growing on lactate-sulfate. The $\Delta \Psi$ and $\Delta \mathrm{pH}$ were both reduced in the

291 mutant (Table 5), which led to a significantly lower PMF in the $r n f A$ mutant relative to 
292 the G20 parent strain. The lower $\Delta \mathrm{pH}$ and PMF in the $r n f A$ mutant shows that the Rnf

293 complex clearly had an impact on the energy conservation system by affecting the

294 proton gradient.

\section{DISCUSSION}

296 The Rnf complex has previously been shown to catalyze the oxidation-reduction

297 reaction between ferredoxin and $\mathrm{NAD}^{+}$(Biegel et al., 2009; Boiangiu et al., 2005). The

298 redox potential of bacterial ferredoxin can vary, but has been reported within the range

299 of -385 to $-460 \mathrm{mV}$ (Smith \& Feinberg, 1990). That is more negative than that of

$300 \mathrm{NAD}^{+} / \mathrm{NADH}$ couple $\left(\mathrm{E}^{\prime}=-280 \mathrm{mV}\right)$ and therefore the transfer of electrons by Rnf from

301 reduced ferredoxin to $\mathrm{NAD}^{+}$releases sufficient energy to generate either a proton or a

302 sodium ion potential (Buckel \& Thauer, 2013). Given that recent studies have

303 demonstrated both proton (Tremblay et al., 2013) and $\mathrm{Na}^{+}$translocation abilities (Biegel

304 \& Müller, 2010), it was imperative to determine which ion Rnf translocates in strain

305 G20. Growth experiments showed that lactate-sulfate grown cells were insensitive to

306 the $\mathrm{Na}^{+}$ionophore, ETH2120, (Figs. S5, S6) but were highly sensitive to the

307 protonophore, TCS (Fig. 2). Resting cells were also shown to be highly sensitive to

308 TCS suggesting that the proton gradient is needed for sulfate reduction. A similar

309 growth profile was observed in C. ljungdahlii, for which this result was interpreted to

310 infer that a proton gradient was needed for growth (Tremblay et al., 2013). . ..

311 When grown on lactate-sulfate or lactate-sulfite, TCS partially inhibited the growth

312 of the parent strain and completely inhibited the growth of $r n f A$ and $r n f D$ mutants (Fig.

313 2). The stronger effect on the mutants suggested that TCS at $5 \mu \mathrm{M}$ was partially

314 dissolving the proton gradient in the parent strain and this was confirmed when cells 
315 were shown to be completely inhibited at $20 \mu \mathrm{M}$ TCS. We would therefore expect that

316 at $5 \mu \mathrm{M}$ TCS, growth processes requiring additional proton motive force (or ATP

317 synthesis) would be more highly inhibited than those requiring less ATP. The use of

318 sulfate as an electron acceptor initially requires energy to activate sulfate to

319 adenosine-5' -phosphosulfate (Gavel et al., 1998). The requirement for energy to

320 activate sulfate may explain why lactate-sulfate grown cells are more susceptible to the

321 action of TCS than are lactate-sulfite-grown cells as the proton gradient generated

322 during sulfate respiration would be needed to make ATP for sulfate activation. The

323 inability of $r n f$ mutants to grow in the presence of $5 \mathrm{uM} \mathrm{TCS}$ is consistent with its role

324 in the generation of a proton motive force. In fact, the magnitude of the proton motive

325 force in rnf mutants is much less than that in the parent strain of G20 (Table 5).

326 Ideally, we would have generated complemented $r n f$ mutants to prove that the

327 observed insertions were not having polar effects on other genes. We have attempted

328 to clone the $r n f A$ and $r n f D$ genes into Escherichia coli as the first step in

329 complementing the mutants. Unfortunately we have not been successful. Another

330 group has experienced similar problems with rnfAB of Clostridum ljungdahlii and

331 suggested that $r n f$ genes may be toxic to E. coli in some cases (Tremblay et al., 2013).

332 Gap analysis was used to show that the insertions did not block transcription of

333 downstream genes providing some evidence that polar effects are not important. As

334 well, we carried out RT-PCR analysis of downstream genes. There was a decreased

335 level of expression of the terminal gene in the Rnf operon ( $r n f F)$ by the $r n f A$ mutant,

336 however, there was little effect of the insertions (mutations) on expression of genes

337 downstream of the operon. 
338 Experiments reported here and elsewhere (Price et al., 2014) show that the rnf

339 mutants are unable to grow on $\mathrm{H}_{2}$, formate and ethanol. These results point to a critical

340 role for Rnf during growth on the above substrates and are consistent with a higher

341 expression level of $r n f$ genes when growing with $\mathrm{H}_{2}$ and sulfate relative to lactate and 342 sulfate (Table 3 ).

343 A proton gradient is thought to be generated during $\mathrm{H}_{2}$ metabolism in Desulfovibrio

344 (Badziong \& Thauer, 1980) and used for the synthesis of ATP. Membrane vesicle

345 experiments carried out in our lab in an attempt to demonstrate the generation of an ion

346 gradient coupled to the oxidation of reduced ferredoxin and reduction of $\mathrm{NAD}^{+}$have

347 been unsuccessful. The protein product of the decaheme cytochrome that precedes the

$348 \quad r n f$ operon has been proposed to accept electrons from hydrogenases and shuttle them to

349 Rnf (Matias et al., 2005; Pereira et al., 2011). However, mutants in this gene had no

350 effect on fitness during growth experiments on ethanol, formate or $\mathrm{H}_{2}$ (Price et al.,

351 2014). This suggests that Rnf is not likely receiving electrons directly from $\mathrm{H}_{2}$. It is

352 more likely that $D$. alaskensis relies extensively on ferredoxin oxidation by Rnf to

353 produce a proton gradient during growth on substrates that do not yield net ATP by

354 substrate-level phosphorylation. For those substrates that do yield ATP by substrate

355 level phosphorylation such as malate, fumarate, pyruvate and lactate, a decreased

356 growth rate and or yield was observed in most cases for rnf mutants (Fig. 1)(Price et al.,

357 2014) suggesting that both Rnf and the F1Fo ATPase are involved in generating a PMF

358 under those conditions.

359 We are not familiar with any studies describing mechanisms of ferredoxin

360 reduction in Desulfovibrio, however, several possible mechanisms have been suggested 
361 (Pereira et al., 2011; Price et al., 2014). During $\mathrm{H}_{2}$ oxidation, these include a possible

362 cytoplasmic electron-bifurcating hydrogenases-linked to a heterodisulfide reductase for

363 which mutants grow poorly on $\mathrm{H}_{2}$ and formate $(\mathrm{Hdr} /$ flox-1). For ethanol oxidation,

364 the acetaldehyde:ferredoxin oxidoreductase could be used, and with pyruvate and

365 lactate oxidation, would involve pyruvate:ferredoxin oxidoreductase.

366 Results from this study are consistent with the fact that $D$. alaskensis Rnf complex

367 functions as a proton rather than a sodium pump and is essential for growth on

368 substrates that do not involve ATP synthesis by substrate-level phosphorylation.

369 Mutation of Rnf limits the development of the PMF and, thus, affects ATP synthesis

370 during growth.

371

373

374

375

376

377

378

379

380

381

382

383

384

385

386

387

388

389

390

391

\section{REFERENCES}

Badziong W, and Thauer RK. 1980. Vectorial electron transport in Desulfovibrio vulgaris (Marburg) growing on hydrogen plus sulfate as sole energy source. Archives of Microbiology 125:167-174.

Beck BJ, and Downs DM. 1999. A periplasmic location is essential for the role of the ApbE lipoprotein in thiamine synthesis in Salmonella typhimurium. Journal of Bacteriology 181:7285-7290.

Biegel E, and Müller V. 2010. Bacterial $\mathrm{Na}^{+}$-translocating ferredoxin: $\mathrm{NAD}^{+}$ oxidoreductase. Proceedings of the National Academy of Sciences 107:18138-18142.

Biegel E, Schmidt S, González JM, and Müller V. 2011. Biochemistry, evolution and physiological function of the Rnf complex, a novel ion-motive electron transport complex in prokaryotes. Cellular and Molecular Life Sciences 68:613-634.

Biegel E, Schmidt S, and Müller V. 2009. Genetic, immunological and biochemical evidence for a Rnf complex in the acetogen Acetobacterium woodii. Environmental Microbiology 11:1438-1443.

Boiangiu CD, Jayamani E, Brügel D, Herrmann G, Kim J, Forzi L, Hedderich R, Vgenopoulou I, Pierik A, and Steuber J. 2005. Sodium ion pumps and hydrogen production in glutamate fermenting anaerobic bacteria. Molecular Microbiology and Biotechnology 10:105-119. 
392

393

394

395

396

397

398

399

400

401

402

403

404

405

406

407

408

409

410

411

412

413

414

415

416

417

418

419

420

421

422

423

424

425

426

427

428

429

430

431

432

433

434

435
Buckel W, and Thauer RK. 2013. Energy conservation via electron bifurcating ferredoxin reduction and proton/ $\mathrm{Na}^{+}$translocating ferredoxin oxidation. Biochimica et Biophysica Acta (BBA)-Bioenergetics 1827:94-113.

Cline JD. 1969. Spectrophotometric determination of hydrogen sulfide in natural waters. Limnology and Oceanography 14:454-458.

Curatti L, Brown CS, Ludden PW, and Rubio LM. 2005. Genes required for rapid expression of nitrogenase activity in Azotobacter vinelandii. Proceedings of the National Academy of Sciences 102:6291-6296.

Gavel OY, Bursakov SA, Calvete JJ, George GN, Moura JJG, and Moura I. 1998. ATP sulfurylases from sulfate-reducing bacteria of the genus Desulfovibrio. A novel metalloprotein containing cobalt and zinc. Biochemistry 37:16225-16232.

Groh JL, Luo Q, Ballard JD, and Krumholz LR. 2005. A method adapting microarray technology for signature-tagged mutagenesis of Desulfovibrio desulfuricans G20 and Shewanella oneidensis MR-1 in anaerobic sediment survival experiments. Applied and Environmental Microbiology 71:7064-7074.

Hess V, Gallegos R, Jones JA, Barquera B, Malamy MH, and Muller V. 2016. Occurrence of ferredoxin: $\mathrm{NAD}^{(+)}$oxidoreductase activity and its ion specificity in several Gram- positive and Gram- negative bacteria. Peerj 4:e1515; DOI 10.7717/peerj.1515.

Jouanneau Y, Jeong HS, Hugo N, Meyer C, and Willison JC. 1998. Overexpression in Escherichia coli of the rnf genes from Rhodobacter capsulatus--characterization of two membrane-bound iron-sulfur proteins. European Journal of Biochemistry 251:54-64.

Kashket E, and Barker SL. 1977. Effects of potassium ions on the electrical and pH gradients across the membrane of Streptococcus lactis cells. Journal of Bacteriology 130:1017-1023.

Kessler RJ, Vande Zande H, Tyson CA, Blondin GA, Fairfield J, Glasser P, and Green DE. 1977. Uncouplers and the molecular mechanism of uncoupling in mitochondria. Proc Natl Acad Sci U S A 74:2241-2245.

Kopke M, Held C, Hujer S, Liesegang H, Wiezer A, Wollherr A, Ehrenreich A, Liebl W, Gottschalk G, and Durre P. 2010. Clostridium ljungdahlii represents a microbial production platform based on syngas. Proc Natl Acad Sci U S A 107:13087-13092.

Krumholz LR, Bradstock P, Sheik CS, Diao Y, Gazioglu O, Gorby Y, and McInerney MJ. 2015. Syntrophic growth of Desulfovibrio alaskensis requires genes for $\mathrm{H}_{2}$ and formate metabolism as well as those for flagellum and biofilm formation. Applied and Environmental Microbiology 81:2339-2348.

Kumagai H, Fujiwara T, Matsubara H, and Saeki K. 1997. Membrane localization, topology, and mutual stabilization of the rnfABC gene products in Rhodobacter capsulatus and implications for a new family of energy-coupling NADH oxidoreductases. Biochemistry 36:5509-5521.

Li X, McInerney MJ, Stahl DA, and Krumholz LR. 2011. Metabolism of $\mathrm{H}_{2}$ by Desulfovibrio alaskensis G20 during syntrophic growth on lactate. Microbiology 157:2912-2921. 
436

437

438

439

440

441

442

443

444

445

446

447

448

449

450

451

452

453

454

455

456

457

458

459

460

461

462

463

464

465

466

467

468

469

470

471

472

473

474

475

476

477

478

479

480

481
Matias PM, Pereira IAC, Soares CM, and Carrondo MA. 2005. Sulphate respiration from hydrogen in Desulfovibrio bacteria: a structural biology overview. Progress in Biophysics and Molecular Biology 89:292-329.

Müller V, Imkamp F, Biegel E, Schmidt S, and Dilling S. 2008. Discovery of a ferredoxin:NAD ${ }^{+}$-oxidoreductase (Rnf) in Acetobacterium woodii: a novel potential coupling site in acetogens. Annals of the New York Academy of Sciences 1125:137-146.

Pereira IAC, Ramos AR, Grein F, Marques MC, Da Silva SM, and Venceslau SS. 2011. A comparative genomic analysis of energy metabolism in sulfate reducing bacteria and archaea. Frontiers in Microbiology 2:1-22.

Pfaffl MW. 2001. A new mathematical model for relative quantification in real-time RT-PCR. Nucleic Acids Res 29:e45.

Price MN, Ray J, Wetmore KM, Kuehl JV, Bauer S, Deutschbauer AM, and Arkin AP. 2014. The genetic basis of energy conservation in the sulfate-reducing bacterium Desulfovibrio alaskensis G20. Frontiers in Microbiology 5:577. doi: 510.3389/fmicb.2014.00577.

Rottenberg H. 1979. The measurement of membrane potential and $\Delta \mathrm{pH}$ in cells, organelles, and vesicles. Methods in enzymology 55:547-569.

Schmehl M, Jahn A, Meyer zu Vilsendorf A, Hennecke S, Masepohl B, Schuppler M, Marxer M, Oelze J, and Klipp W. 1993. Identification of a new class of nitrogen fixation genes in Rhodobacter capsalatus: a putative membrane complex involved in electron transport to nitrogenase. Molecular and General Genetics 241:602-615.

Seedorf H, Fricke WF, Veith B, Brüggemann H, Liesegang H, Strittmatter A, Miethke M, Buckel W, Hinderberger J, and Li F. 2008. The genome of Clostridium kluyveri, a strict anaerobe with unique metabolic features. Proceedings of the National Academy of Sciences 105:2128-2133.

Shirvan M, Schuldiner S, and Rottem S. 1989. Volume regulation in Mycoplasma gallisepticum: evidence that $\mathrm{Na}^{+}$is extruded via a primary $\mathrm{Na}^{+}$pump. Journal of Bacteriology 171:4417-4424.

Smith ET, and Feinberg BA. 1990. Redox properties of several bacterial ferredoxins using square wave voltammetry. J Biol Chem 265:14371-14376.

Tremblay P-L, Zhang T, Dar SA, Leang C, and Lovley DR. 2013. The Rnf complex of Clostridium ljungdahlii is a proton-translocating ferredoxin: NAD+ oxidoreductase essential for autotrophic growth. Mbio 4:e0406-00412.

Yan Y, Yang J, Dou Y, Chen M, Ping S, Peng J, Lu W, Zhang W, Yao Z, and Li H. 2008. Nitrogen fixation island and rhizosphere competence traits in the genome of root-associated Pseudomonas stutzeri A1501. Proceedings of the National Academy of Sciences 105:7564-7569. 
482 Table 1. List of primers used for gap analysis in the $r n f$ operon.

\begin{tabular}{|l|l|l|}
\hline Gap & Forward primer & Reverse primer \\
\hline Gap CC $(c y t C / r n f C)$ & GGCATTCACGGCCTGTGCCT & CTTGTCGCCGGGGTGATCGG \\
\hline Gap CD $(r n f C / r n f D)$ & CCTGCTGGGACGCTACAGCG & ATGCCGTGTATGGTGCGCCC \\
\hline Gap DG $(r n f D / r n f G)$ & GGCAAGGCCGCCATGGTCAT & TGTACTCGGCCCCCGTGGAG \\
\hline Gap GE $(r n f G / r n f E)$ & ATCGGCTGCATGGTTGCCGT & ATTGGCGGACTTGGTGACCG \\
\hline Gap EA $(r n f E / r n f A)$ & GGGCTTGTTCTGGGCGCCAT & CCGCCCATGCCCAGACTGAC \\
\hline Gap BE $(r n f B / r n f F)$ & AAAGCCTGCCTCGCGTTCGG & AAGCCCCAGCAGACCGCATG \\
\hline
\end{tabular}
483

48Hable 2. Primers used for the RT-qPCR experiments

\begin{tabular}{|c|c|c|}
\hline Primer & Sequence & Target gene \\
\hline Dde_587 forward & 5'-AACCGTGGGTTATCGCCATT-3' & \multirow[t]{2}{*}{$r n f F$ gene } \\
\hline Dde_587 reverse & 5'-ATGGCTGTACATGCGTTTGC-3' & \\
\hline Dde_589 forward & 5'-AAGGGCAGGTAGTGCTGATG-3' & \multirow{2}{*}{$\begin{array}{l}\text { Putative } \\
\text { regulator gene }\end{array}$} \\
\hline Dde_589 reverse & 5'-GGTAAACTTCACGCCTTCGC-3' & \\
\hline Dde_590 forward & 5'-GCCTGCGGCTTAATTTCGAG-3' & \multirow{2}{*}{$\begin{array}{l}\text { Cardiolipin } \\
\text { synthase gene }\end{array}$} \\
\hline Dde_590 reverse & 5'-ACGGTTTTCCAGTTCGCTCA-3' & \\
\hline 16s forward & 5'-ACGGTTGGAAACGACTGCTA-3' & \multirow{2}{*}{$\begin{array}{l}\text { 16s rRNA } \\
\text { gene }\end{array}$} \\
\hline 16s reverse & 5'-AGCTAATCAGACGCGGACTC-3' & \\
\hline
\end{tabular}

485

486 Table 3. Normalized expression levels of genes within the rnf operon (from

487 (Krumholz et al., 2015)). Expression was determined with the parent strain of $D$.

488 alaskensis G20 during growth in pure culture with the indicated electron donors

489 and acceptors and in coculture with S. aciditrophicus (SB) or with S. wolfei (SW) in

490 the presence of benzoate or butyrate, respectively, as electron donors and sulfate

491 as the electron acceptor.

\begin{tabular}{|l|l|l|l|l|l|l|}
\hline Gene & Function & $\begin{array}{l}\text { Lactate/ } \\
\text { Sulfate }\end{array}$ & $\begin{array}{l}\mathrm{H}_{2} / \\
\text { Sulfate }\end{array}$ & $\begin{array}{l}\mathrm{H}_{2} / \\
\text { Sulfite }\end{array}$ & $\mathrm{SB}$ & $\mathrm{SW}$ \\
\hline Dde_0580 & cyt c family protein & 3.17 & 8.33 & 6.18 & 6.02 & 14.36 \\
\hline Dde_0581 & RnfC subunit & 3.05 & 6.68 & 6.12 & 5.61 & 13.50 \\
\hline Dde_0582 & RnfD subunit & 1.90 & 4.41 & 3.34 & 2.68 & 7.73 \\
\hline Dde_0583 & RnfG subunit & 2.83 & 6.35 & 5.19 & 5.43 & 10.07 \\
\hline Dde_0584 & RnfE subunit & 1.86 & 4.95 & 3.80 & 3.39 & 7.63 \\
\hline Dde_0585 & RnfA subunit & 2.24 & 5.78 & 4.23 & 2.98 & 8.41 \\
\hline Dde_0586 & RnfB subunit & 2.18 & 4.39 & 4.16 & 1.48 & 8.09 \\
\hline Dde_0587 & RnfF subunit & 2.20 & 4.90 & 5.25 & 1.94 & 10.15 \\
\hline
\end{tabular}

492

493

494

495

496

497 
498

499

500

501

502

503

504

505

506

507

508

509

510

511

512

513

514

515

516

517

518

519

520

521

522

523

524

525

526

527

528

529

530

531
Table 4. Gene expression in D. alaskensis rnfA and $r n f D$ mutants relative to the parental strain using RT-qPCR. And normalized with the 16s rRNA gene.

\begin{tabular}{|l|l|l|l|}
\hline Mutant type & Dde_587 & Dde_589 & Dde_590 \\
\hline$r n f A$ & $0.227 \pm 0.255$ & $0.608 \pm 0.097$ & $0.589 \pm 0.253$ \\
\hline$r n f D$ & $1.955 \pm 0.624$ & $1.155 \pm 0.078$ & $0.972 \pm 0.420$ \\
\hline
\end{tabular}

Table 5. Magnitude of the $\Delta \mathrm{pH}, \Delta \Psi$ and total proton motive force of the D. alaskensis G20 parent strain and the rnfA mutant growing on lactate and sulfate. Standard deviation in parentheses. Value for the rnfA mutant were statistically different from the parent strain at $\mathrm{p}<0.05$.

\begin{tabular}{|l|l|l|}
\hline Measurement & Parent Strain & rnfA mutant \\
\hline$\Delta \Psi$ & $-158 \mathrm{mV}(2.1)$ & $-117 \mathrm{mV}(3.2)$ \\
\hline$\Delta \mathrm{pH}$ & $0.43(0.057)$ & $0.29(0.015)$ \\
\hline PMF & $-185 \mathrm{mV}(3.1)$ & $-135 \mathrm{mV}(4.1)$ \\
\hline
\end{tabular}


532

533

534

\section{Figures}

Fig. 1
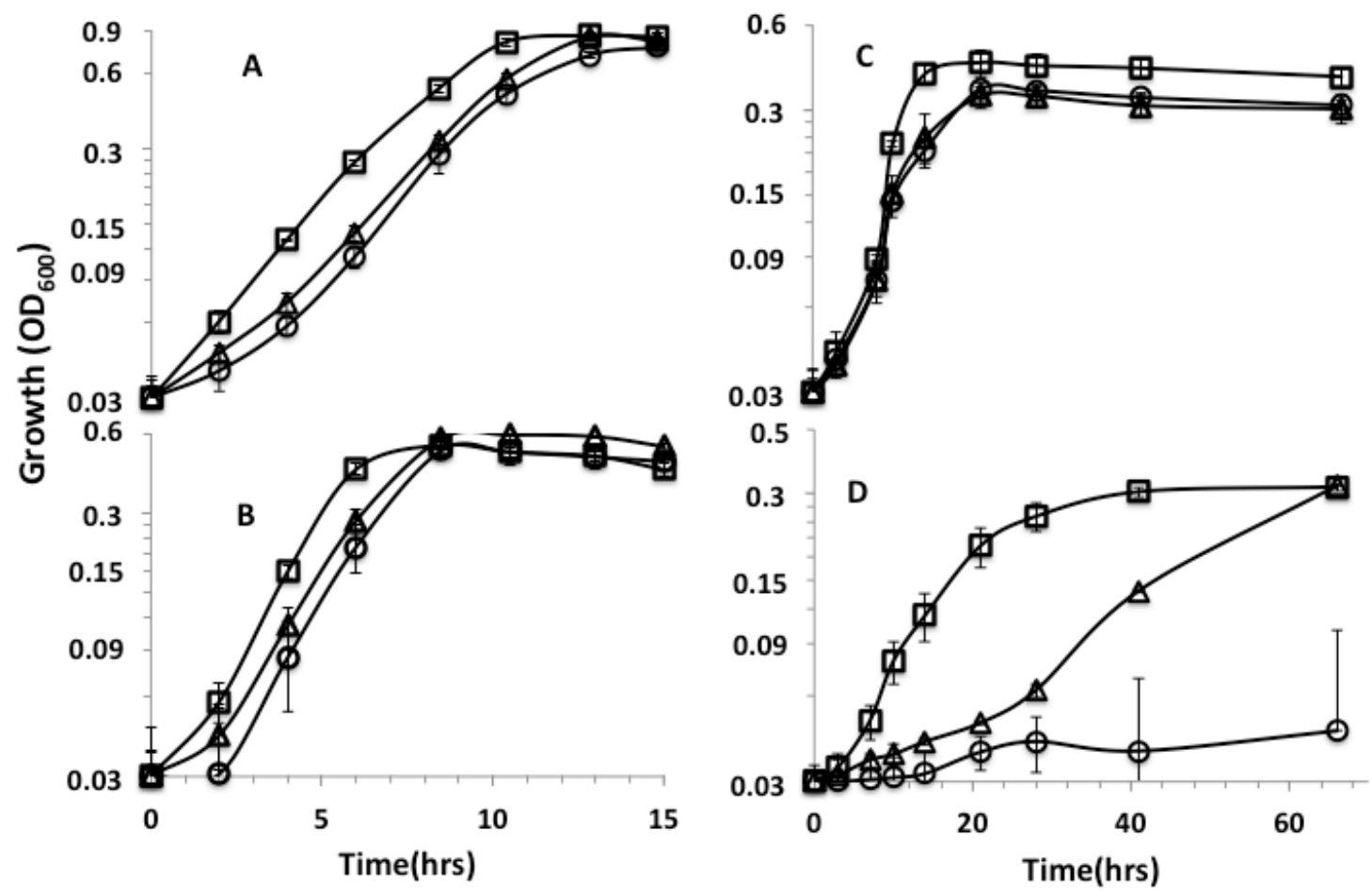

535

536

537

Figure 1. Growth curves on (A) lactate-sulfate (B) lactate-sulfite (C) pyruvate-sulfate 538 and (D) formate-sulfate. Curves are for D. alaskensis parent strain ( $\square$ ) rnfA (O) and 539 $r n f \mathrm{D}(\triangle)$ mutants. Error bars show standard deviation. 


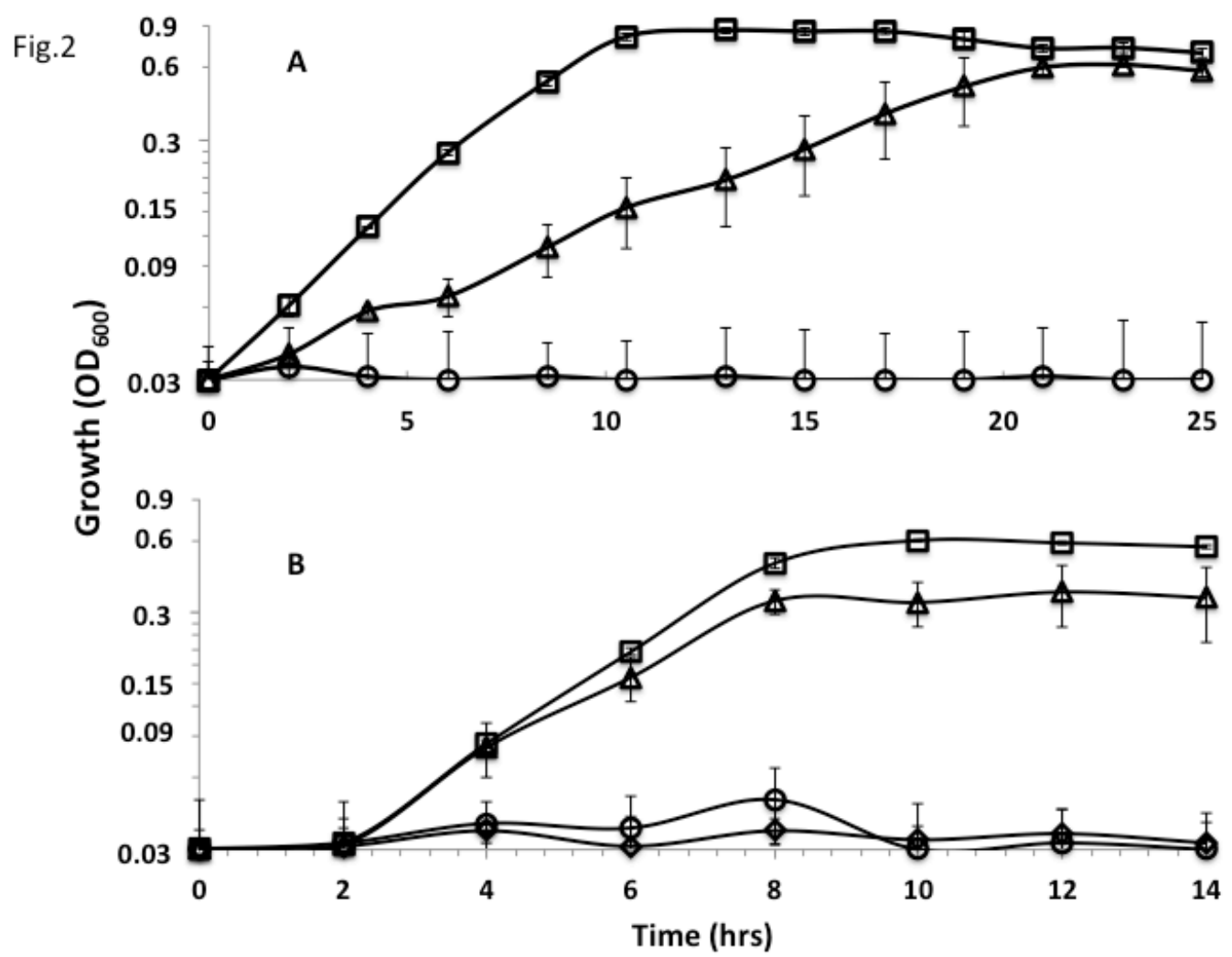

542 Figure 2. Growth curves with (A) lactate-sulfate and (B) lactate sulfite for D. alaskensis 543 parent strain no addition $(\square)$ and with $5 \mu \mathrm{M}(\triangle)$ or $20 \mu \mathrm{M}(\diamond)$ TCS. Growth curve of 544 the rnfA mutant with $5 \mu \mathrm{M}$ TCS $(O)$ is also shown. Error bars show standard 545 deviation.

546

547

548

549

550

551

552

553

554

555

556

557

558 


\section{Table 1 (on next page)}

Table 1.

Table 1. List of primers used for gap analysis in the rnf operon. 
1 Table 1. List of primers used for gap analysis in the $r n f$ operon.

2

\begin{tabular}{|l|l|l|}
\hline Gap & Forward primer & Reverse primer \\
\hline Gap CC $(c y t C / r n f C)$ & GGCATTCACGGCCTGTGCCT & CTTGTCGCCGGGGTGATCGG \\
\hline Gap CD $(r n f C / r n f D)$ & CCTGCTGGGACGCTACAGCG & ATGCCGTGTATGGTGCGCCC \\
\hline Gap DG $(r n f D / r n f G)$ & GGCAAGGCCGCCATGGTCAT & TGTACTCGGCCCCCGTGGAG \\
\hline Gap GE $(r n f G / r n f E)$ & ATCGGCTGCATGGTTGCCGT & ATTGGCGGACTTGGTGACCG \\
\hline Gap EA $(r n f E / r n f A)$ & GGGCTTGTTCTGGGCGCCAT & CCGCCCATGCCCAGACTGAC \\
\hline Gap BE $(r n f B / r n f F)$ & AAAGCCTGCCTCGCGTTCGG & AAGCCCCAGCAGACCGCATG \\
\hline
\end{tabular}

3 


\section{Table 2 (on next page)}

Table 2.

Table 2. Primers used for the RT-qPCR experiments. 
1 Table 2. Primers used for the RT-qPCR experiments

\begin{tabular}{|c|c|c|}
\hline Primer & Sequence & Target gene \\
\hline Dde_587 forward & 5'-AACCGTGGGTTATCGCCATT-3' & \multirow{2}{*}{ rnfF gene } \\
\hline Dde_587 reverse & 5'-ATGGCTGTACATGCGTTTGC-3' & \\
\hline Dde_589 forward & 5'-AAGGGCAGGTAGTGCTGATG-3' & \multirow{2}{*}{$\begin{array}{l}\text { Putative } \\
\text { regulator gene }\end{array}$} \\
\hline Dde_589 reverse & 5'-GGTAAACTTCACGCCTTCGC-3' & \\
\hline Dde_590 forward & 5'-GCCTGCGGCTTAATTTCGAG-3' & \multirow{2}{*}{$\begin{array}{l}\text { Cardiolipin } \\
\text { synthase gene }\end{array}$} \\
\hline Dde_590 reverse & 5'-ACGGTTTTCCAGTTCGCTCA-3' & \\
\hline 16s forward & 5'-ACGGTTGGAAACGACTGCTA-3' & \multirow{2}{*}{ 16s rRNA gene } \\
\hline 16s reverse & 5'-AGCTAATCAGACGCGGACTC-3' & \\
\hline
\end{tabular}

2

3 


\section{Table 3(on next page)}

Table 3.

Table 3. Normalized expression levels of genes within the rnf operon (from (Krumholz et al., 2015) ). Expression was determined with the parent strain of $D$. alaskensis $\mathrm{G} 20$ during growth in pure culture with the indicated electron donors and acceptors and in coculture with S. aciditrophicus (SB) or with S. wolfei (SW) in the presence of benzoate or butyrate, respectively, as electron donors and sulfate as the electron acceptor. 
1 Table 3. Normalized expression levels of genes within the $r n f$ operon (from (Krumholz et 2 al. 2015a)). Expression was determined with the parent strain of D. alaskensis G20 during 3 growth in pure culture with the indicated electron donors and acceptors and in coculture 4 with S. aciditrophicus (SB) or with S. wolfei (SW) in the presence of benzoate or butyrate, 5 respectively, as electron donors and sulfate as the electron acceptor.

\begin{tabular}{|l|l|l|l|l|l|l|}
\hline Gene & Function & $\begin{array}{l}\text { Lactate/ } \\
\text { Sulfate }\end{array}$ & $\begin{array}{l}\mathrm{H}_{2} / \\
\text { Sulfate }\end{array}$ & $\begin{array}{l}\mathrm{H}_{2} / \\
\text { Sulfite }\end{array}$ & SB & SW \\
\hline Dde_0580 & cyt c family protein & 3.17 & 8.33 & 6.18 & 6.02 & 14.36 \\
\hline Dde_0581 & RnfC subunit & 3.05 & 6.68 & 6.12 & 5.61 & 13.50 \\
\hline Dde_0582 & RnfD subunit & 1.90 & 4.41 & 3.34 & 2.68 & 7.73 \\
\hline Dde_0583 & RnfG subunit & 2.83 & 6.35 & 5.19 & 5.43 & 10.07 \\
\hline Dde_0584 & RnfE subunit & 1.86 & 4.95 & 3.80 & 3.39 & 7.63 \\
\hline Dde_0585 & RnfA subunit & 2.24 & 5.78 & 4.23 & 2.98 & 8.41 \\
\hline Dde_0586 & RnfB subunit & 2.18 & 4.39 & 4.16 & 1.48 & 8.09 \\
\hline Dde_0587 & RnfF subunit & 2.20 & 4.90 & 5.25 & 1.94 & 10.15 \\
\hline
\end{tabular}

6 


\section{Table 4 (on next page)}

Table 4.

Table 4. Gene expression in $D$. alaskensis $r n f A$ and $r n f D$ mutants relative to the parental strain using RT-qPCR. And normalized with the 16s rRNA gene. 
1 Table 4. Gene expression in D. alaskensis $r n f A$ and $r n f D$ mutants relative to the parental

2 strain using RT-qPCR. And normalized with the 16s rRNA gene.

3

\begin{tabular}{|l|l|l|l|}
\hline Mutant type & Dde_587 & Dde_589 & Dde_590 \\
\hline$r n f A$ & $0.227 \pm 0.255$ & $0.608 \pm 0.097$ & $0.589 \pm 0.253$ \\
\hline$r n f D$ & $1.955 \pm 0.624$ & $1.155 \pm 0.078$ & $0.972 \pm 0.420$ \\
\hline
\end{tabular}

4

5 


\section{Table 5 (on next page)}

Table 5. Magnitude of the $\Delta \mathrm{pH}, \Delta \Psi$ and total proton motive force of the $\mathrm{D}$. alaskensis G20 parent strain and the rnfA mutant growing on lactate and sulfate.

Table 5. Magnitude of the $\Delta \mathrm{pH}, \Delta \Psi$ and total proton motive force of the $D$. alaskensis $G 20$ parent strain and the rnfA mutant growing on lactate and sulfate. Standard deviation in parentheses. Value for the rnfA mutant were statistically different from the parent strain at $p<0.05$. 
1 Table 5. Magnitude of the $\Delta \mathrm{pH}, \Delta \Psi$ and total proton motive force of the D. alaskensis $\mathrm{G} 20$ 2 parent strain and the $r n f A$ mutant growing on lactate and sulfate. Standard deviation in 3 parentheses. Value for the $r n f A$ mutant were statistically different from the parent strain at $4 \quad \mathrm{p}<0.05$.

5

\begin{tabular}{|l|l|l|}
\hline Measurement & Parent Strain & rnfA mutant \\
\hline$\Delta \Psi$ & $-158 \mathrm{mV}(2.1)$ & $-117 \mathrm{mV}(3.2)$ \\
\hline$\Delta \mathrm{pH}$ & $0.43(0.057)$ & $0.29(0.015)$ \\
\hline PMF & $-185 \mathrm{mV}(3.1)$ & $-135 \mathrm{mV}(4.1)$ \\
\hline
\end{tabular}

6 


\section{Figure 1 (on next page)}

Figure 1-Growth curves of parent strain and mutants.

Figure 1. Growth curves on (A) lactate-sulfate (B) lactate-sulfite (C) pyruvate-sulfate and (D) formate-sulfate. Curves are for $D$. alaskensis parent strain $(f) r n f A(\square)$ andnfD $(r)$ mutants. Error bars show standard deviation. 
Fig. 1

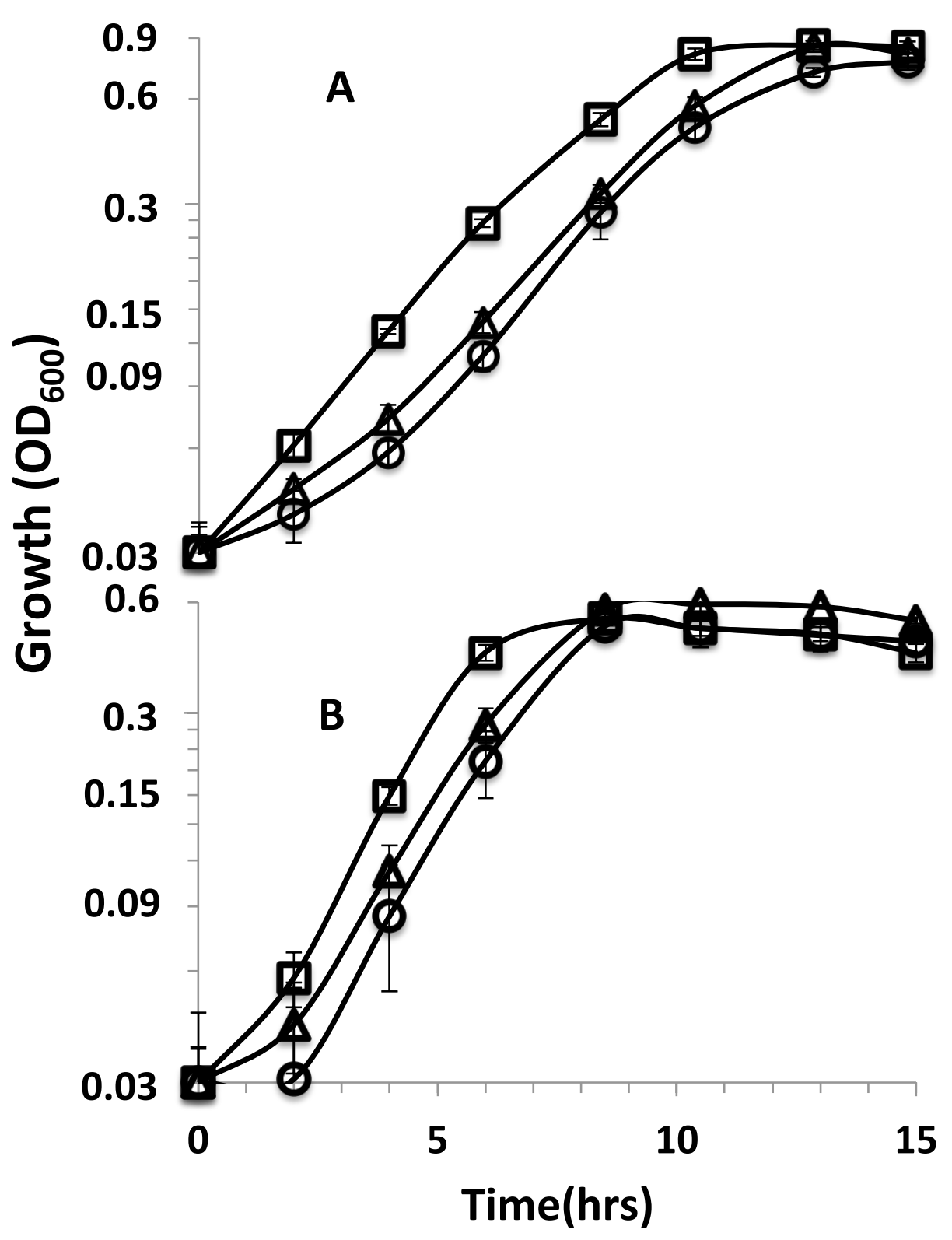

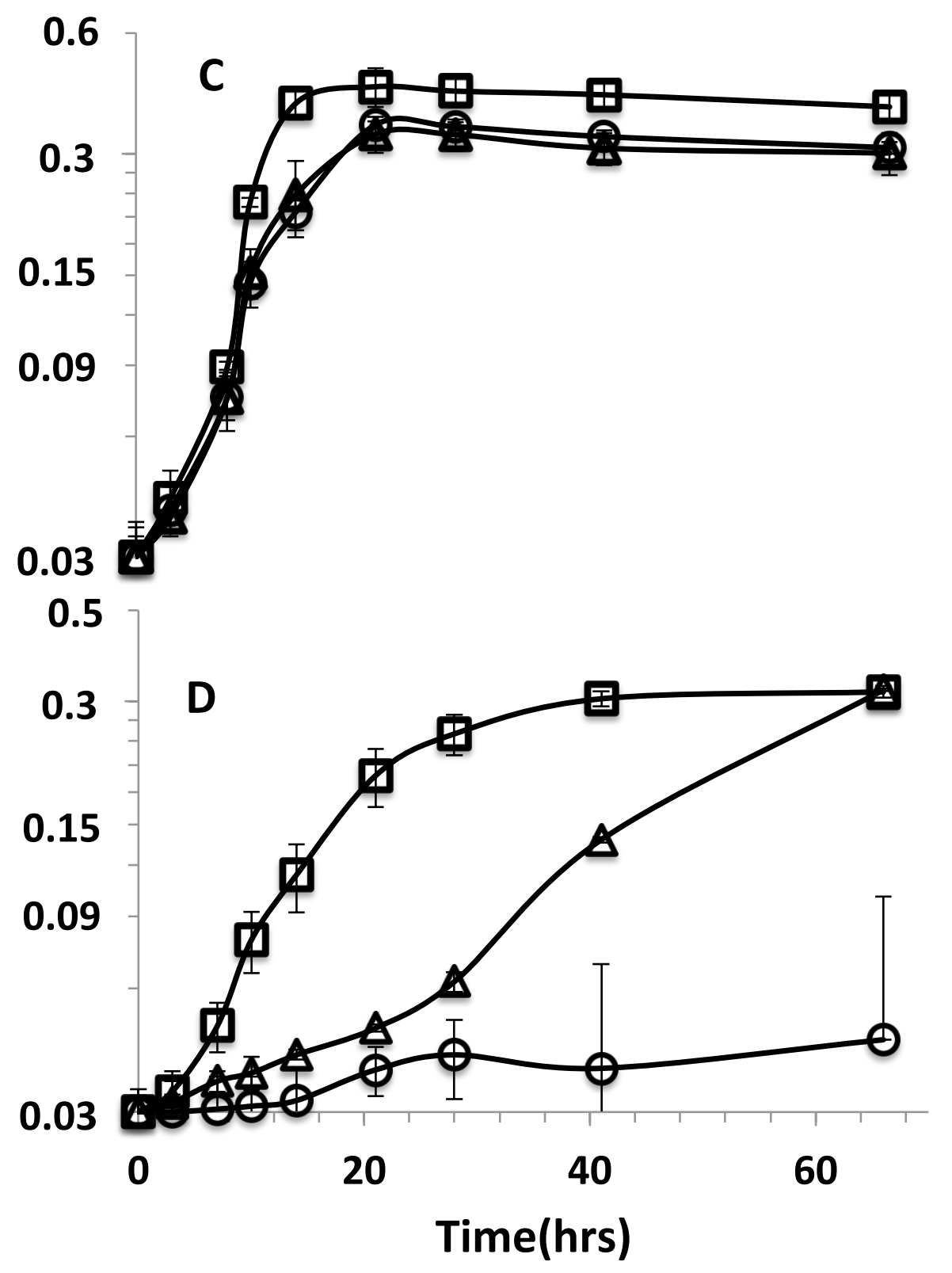




\section{Figure 2 (on next page)}

Figure 2. Effect of TCS on parent strain and mutants.

Figure 2. Growth curves with (A) lactate-sulfate and (B) lactate sulfite for D. alaskensis parent strain no addition $(f)$ and with $5 \mu \mathrm{M}(r)$ or $20 \mu \mathrm{M}\left({ }^{-}\right)$TCS. Growth curve of the rnfA mutant with $5 \mu \mathrm{M}$ TCS $(\square)$ is also shown. Error bars show standard deviation. 


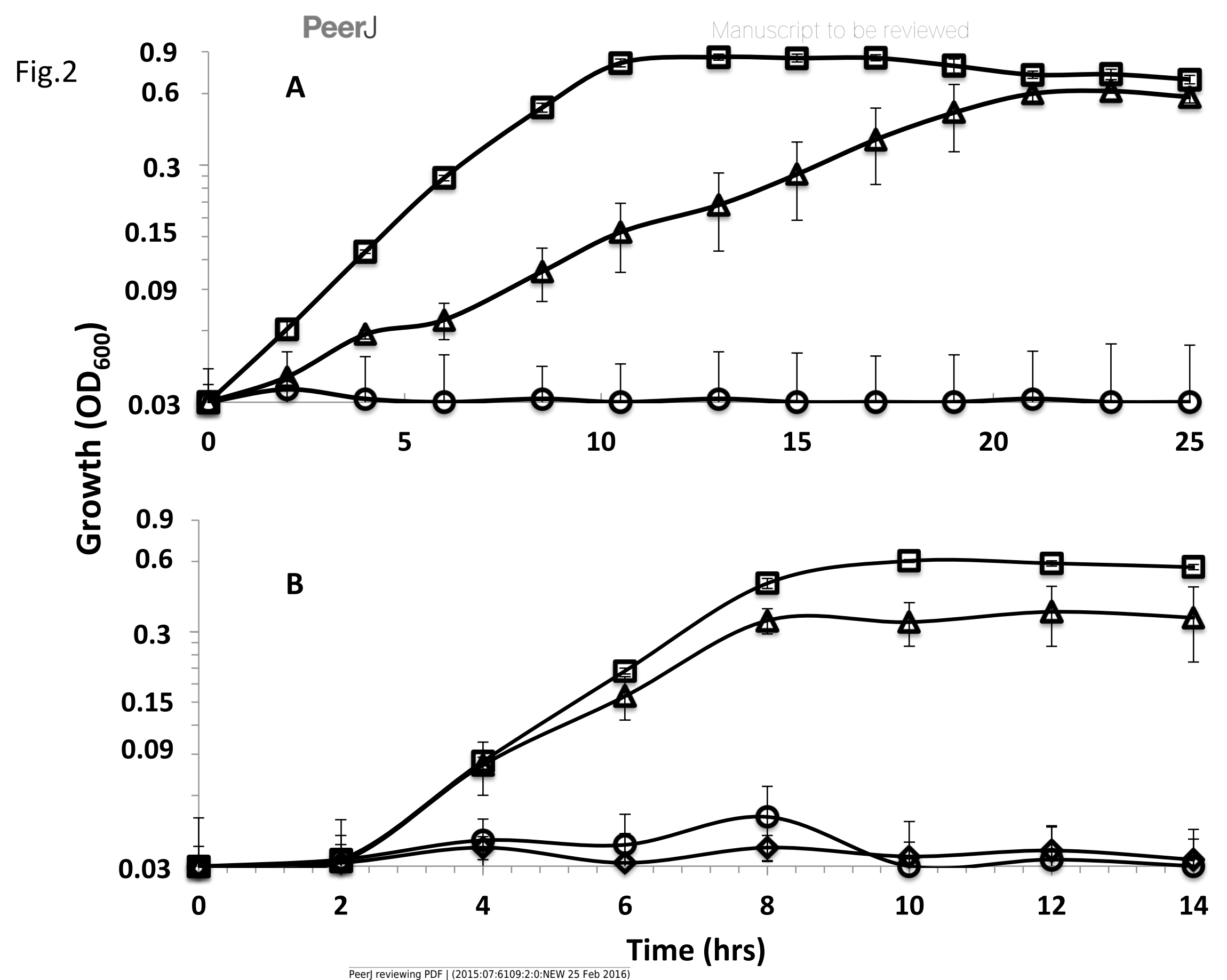

